\title{
Utilization of Antihypertensive Drugs in Diabetic Patients in Sultan Qaboos University Hospital
}

\author{
Khalil Al Ajmi ${ }^{1 *}$, Aly Abdel Rahman ${ }^{2}$ and Adel Ahmidat ${ }^{3}$ \\ ${ }^{1}$ Intern, Department of Surgery, Sultan Qaboos University, Oman \\ ${ }^{2}$ Associate Professor, Department of Pharmacology, College of Medicine and Health Sciences, Sultan Qaboos University, Oman \\ ${ }^{3}$ Consultant Obstetrician \& Gynecologist, York Teaching Hospital, United Kingdom
}

*Corresponding author: Khalil Al Ajmi, Intern, Department of Surgery, Sultan Qaboos University, Muscat, Oman

\section{ARTICLE INFO}

Received: 幽 December 23, 2020

Published: 慧 January 05, 2021

Citation: Khalil Al Ajmi, Aly Abdel Rahman, Adel Ahmidat. Utilization of Antihypertensive Drugs in Diabetic Patients in Sultan Qaboos University Hospital. Biomed J Sci \& Tech Res 32(5)2021. BJSTR. MS.ID.005328.

\begin{abstract}
Hypertension is very common among patients with diabetes. Approximately, 10 to $30 \%$ of type 1 and $60 \%$ of type 2 diabetic patients have hypertension. The patterns of utilization of antihypertensive drugs in diabetic patients were studied retrospectively in 101 hypertensive diabetic patients. Study findings focused on showing if there is any reason behind the differences. This study helps to implement interventions aimed at improving antihypertensive drug utilization and reducing medication errors. Drug factors such as dosage form, average daily dose, and adverse drug reactions were assessed. 53.5\% of patients were on angiotensin II receptor blockers. 59.4\% of the patients were on multiple drug therapy. Average daily dosages were almost comparable with the American Society of Hypertension and the International Society of Hypertension guidelines. Patients in the age group $(\geq 60$ ) used $\beta$-blockers with a higher percentage than patients of the age group (18-59). Vasodilators, calcium channel blockers, and $\beta$-blockers showed higher use percentages in patients with diabetic nephropathy compared to patients with no nephropathy whereas the percentage of angiotensin-converting-enzyme inhibitors was higher in no nephropathy status. $84.2 \%$ of patients had uncontrolled systolic blood pressure, and $43.6 \%$ of patients had uncontrolled diastolic blood pressure.
\end{abstract}

\section{Introduction}

Hypertension is a major worldwide health issue causing cardiovascular morbidity that affects about $26 \%$ of all adults worldwide. Hypertension is defined as a blood pressure $\geq 140 / 90$ $[1,2]$. Diabetes Mellitus (DM) is an endocrine disorder. Surveys that were carried out in Oman in 2000 and 2008 found that the prevalence of $\mathrm{T} 2 \mathrm{DM}$ was $11.1 \%$ and $9.6 \%$, respectively [3]. It requires continuous attention to glucose monitoring, exercise, diet, and medication to achieve appropriate glycemic control [4]. Hypertension is very common among patients with diabetes. Roughly, 10 to $30 \%$ of type 1 and $60 \%$ of type 2 diabetic patients have hypertension [5]. High blood pressure and diabetes tend to coexist together because they have common physiological traits. High blood pressure becomes even more problematic in the setting of diabetes. Diabetes increases the quantity of fluid in the body, which tends to increase blood pressure [6]. In addition, it can decrement the distensibility of the blood vessels, increasing mean arterial pressure [7]. Furthermore, it causes changes in the way the body handles and produces insulin, which can directly raise blood pressure [8]. Appropriate reduction in blood pressure with antihypertensive agents helps to prevent diabetic microvascular and macrovascular complications [9]. Johnson and Singh found that the majority of hypertensive diabetic patients were on multidrug regimens (2005). Diabetes mellitus is now considered the most common cause of end-stage renal disease [10]. The selection of antihypertensive medications should take into consideration the kidney function status [11].

Pharmacologic management should be initiated when blood pressure is $\geq 140 / 90 \mathrm{~mm} \mathrm{Hg}$, irrespective of age [12]. A blood pressure value of $<130 / 80 \mathrm{mmHg}$ was considered as good control of hypertension in hypertensive diabetic patients [13]. It was demonstrated that blood pressure control in patients with diabetes is worse than those without diabetes, and less intensive antihypertensive drug therapy is given to them [14]. The antihypertensive drugs include angiotensin-converting enzyme inhibitors (ACEI), calcium-channel blockers, angiotensin II receptor blockers (ARBs), beta blockers, diuretics and renin inhibitors [15]. 
In Oman, drugs available for hypertension in diabetic patients include ACEI, beta blockers, calcium channel blockers, diuretics, methyl dopa, prazosin, valsartan/hydrochlorothiazide [15]. Firstline therapy in hypertension without other compelling indications for other agents includes thiazide/thiazide like diuretics, ACEI, ARB, $\beta$-blockers, or long-acting CCBs. If blood pressure is still elevated with systolic blood pressure $\geq 20 \mathrm{mmHg}$ or diastolic blood pressure $\geq 10 \mathrm{mmHg}$ greater than target blood pressure, then second-line therapy is administered. Second-line therapy is comprised of combinations of first-line therapy [16]. The 2016 National Heart Foundation guidelines does not recommend $\beta$-blockers any longer as first-line agents in the management of hypertension [17]. This is reflected by the fact that two meta-analyses suggested an increased risk of stroke associated with their use [18-20]. Diuretics potentiate the effect of antihypertensive drugs, including calcium channel blockers. The elderly and blacks respond better to diuretics than do nonblacks and younger patients [21]

In diabetic patients, ACEI and ARB, which seem to have the potential to decrease blood glucose, may have particular benefits in preventing microalbuminuria, worsening of kidney function or other microvascular complications [22]. $\beta$-blockers and thiazide diuretics are known to reduce insulin sensitivity and transiently increase low-density lipoprotein cholesterol levels and triglycerides, whereas calcium channel blockers are metabolically neutral and angiotensin-receptor blockers, angiotensinconverting enzyme inhibitors, and renin inhibition are beneficial in increasing insulin sensitivity [23]. Selective $\beta 1$-blockers are indicated in diabetic patients with ischemic heart disease without contraindications. $\beta$-blockers cannot help in renoprotection or improvement of glycemic control [24]. Drugs of choice used for the treatment of hypertension in diabetic patients with nephropathy are ACEI and ARB. ACEI, ARB, dihydropyridine calcium channel blockers (DHP-CCB) and thiazide diuretics are the drugs of choice for the treatment of hypertension in diabetic patients without nephropathy [25]. Patients with poor health literacy have little knowledge and consequently, little medication knowledge about how to manage their illness [26]. Decreased compliance with antihypertensive drugs can be affiliated to the lack of understanding of the potential benefits of treatment [27]. More interventions are required in order to improve the medical care of this category of patients [28]. A strong and consistent association between health literacy and diabetes outcomes was observed [29]. Compliance with antihypertensive drugs was higher in patients with higher cardiovascular risk. Possibly owing to increased motivation to follow the treatment course and awareness of the importance of treatment [30]. Mental illness increased the risk of non-compliance to antihypertensive drugs by $8 \%$ [31]. There is substantial agreement on the positive relationship between increased age and higher levels of compliance [32]. Treating resistant hypertension requires a rational combination of antihypertensive drugs and should include a diuretic because blood pressure lowering can lead to sodium and volume retention, which is often the cause for treatment resistance hypertension.

The commonest adverse drug reactions of antihypertensive drugs include dizziness (9\%), ankle swelling (7\%), headache (5\%), fatigue (4\%), chest discomfort (3\%), and cough (3\%) [33]. The prevalence of adverse drug reactions was not significantly different in women from men. Age did not predict the occurrence of side-effects nor the number of them. Patients on a diuretic reported adverse drug reactions more frequently than any other drug class. DHP-CCB decreases systemic blood pressure and raise intraglomerular capillary pressure. This is responsible for pressure-mediated glomerular injury and leads to an increase in proteinuria and faster deterioration of glomerular filtration rate $[34,35]$. This study was initiated to evaluate and explore the patterns of utilization of antihypertensive drugs in diabetic patients in Sultan Qaboos University Hospital (SQUH).

\section{Aim}

To identify utilization patterns of antihypertensive drugs among hypertensive diabetic patients in SQUH.

\section{Rationale}

This study is aimed at assessing the quality of antihypertensive drug use, thus ensuring effective and safe antihypertensive drug utilization. The findings of this study can be used for national comparisons of drug utilization, which will help to provide feedback to prescribers. This will help to implement interventions aimed at improving antihypertensive drug utilization and reducing medication errors.

\section{Specific Objectives}

a) To evaluate the utilization of antihypertensive therapy in hypertensive diabetic patients.

b) To correlate age and nephropathy with antihypertensive drugs utilization.

c) To identify single and multiple drug therapy.

d) To assess the effectiveness of antihypertensive drugs in lowering blood pressure values in hypertensive diabetic patients.

\section{Patients and Methods}

\section{Type of Study}

A retrospective cohort study.

\section{Patient Population}

A total of 101 hypertensive diabetic patients were included in this study. 


\section{Ethical Concerns}

Ethical approval was obtained from the Medical Research \& Ethics Committee before the commencement of the study.

\section{Data Collection}

Medical Record Numbers (MRN) were obtained from the diabetes outpatient clinic in the Department of Endocrinology. A datasheet instrument (Appendix A) was used to collect outpatient's data from SQUH Trak Care system. All information was entered through a computer to SPSS software version 23. The data form comprised of demographic data of patients, their blood pressure, comorbidities, laboratory test results, antihypertensive drugs data, information about other medications and additional notes about the patients. All the patients' MRNs were encoded with $(1,2,3,4,5)$ pattern in order to preserve confidentiality and anonymity. The MRNs of the patients of the study were randomly selected from the session appointment lists in the Department of Endocrinology. The time period allocated to collect patients' information was sufficient to obtain data of 5 patients per day, which is reasonable enough considering the long time needed to read the long patient history of many patients who follow up for more than 20 years. Random sampling was used to ensure that the study sample is truly representative of the SQUH population.

\section{Inclusion Criteria}

a) Patients with diabetic hypertension.

b) Age $\geq 18$ years.

c) Patients whose medications are marked as accepted status.

\section{Exclusion Criteria}

a) Patients whose medications are marked as pending status.

b) Patients whose medications are marked as discontinued status.

\section{The Following Data Were Collected}

\section{A. Patients}

a) The time frame of the study patients' visits was from February to June 2016.

b) The patients were divided into two age groups: group 1 (age: 18-59 years) and group 2 (age: $\geq 60$ years). Influence factors like sex and comorbidities information were collected.

\section{B. Blood Pressure}

Value of $<130 / 80 \mathrm{mmHg}$ was considered as good control of hypertension in diabetic patients and was used to evaluate the degree of control of hypertension in hypertensive diabetic patients.

Nephropathy status was reported as a) Coexistent diabetic nephropathy.

b) No diabetic nephropathy.

\section{Antihypertensive Drugs}

a) Data of drug prescription patterns were compared on the basis of usage of drug groups, drugs, monotherapy, multiple drug therapy, and fixed-dose combination.

b) Average daily dose was determined and compared with the recommended dose.

c) Medications used in each age group were reported.

Antihypertensive drug combinations of the designated drugs were identified using stacked bar charts generated from SPSS software. Drug combinations were illustrated using 101 stacked bar charts for every patient in this study. The bar charts with identical color labels meant that they were identical drug combinations, and therefore, they were omitted along with single drugs stacked bar charts. Stacked bar charts with distinct color labels were not omitted. They depicted the different drug combinations prescribed to hypertensive diabetic patients.

\section{Data Analysis}

The information on the data form was entered into a database on the Statistical Package for the Social Sciences (SPSS) software version 23.0 (IBM Corp. Released 2015. IBM SPSS Statistics for Windows, Version 23.0. Armonk, NY: IBM Corp). SPSS software performed the tasks of generating bar charts and calculating p-values of chi-square test. Chi-square test was used to compare the percentages of antihypertensive drugs in nephropathy status and age groups. Arithmetic mean values, numbers, percentages, ranges, and standard deviation of each variable were measured by SPSS. Data were analyzed by SPSS software version 23. P $<0.05$ was considered as a significant value. At the end of executing these commands on the SPSS software, data interpretation and graphical presentation were made.

\section{Results}

\section{Demographic Data}

Table 1 shows the demographics of the 101 patients who were selected. The mean age was 58 years; 51 patients were males, and 50 were females, and all patients were Omanis. There were significantly fewer cases of nephropathy than without nephropathy (24 with nephropathy/ 77 without nephropathy). The mean systolic and diastolic blood pressure of the study sample were 149.56 $\mathrm{mmHg}$ and $77.06 \mathrm{mmHg}$, respectively. The rest of the demographic data are summarized in Table 1.

\section{Average Daily Dose}

The average daily dose was calculated for every antihypertensive drug (Table 2). Two patients used a prescribed 
daily dose of spironolactone that ranged between $25 \mathrm{mg}$ and 100 mg with an average daily dose of $62.5 \mathrm{mg}$. Only one patient used the drug propranolol with an average daily dose of $20 \mathrm{mg}$. The

Table 1: Demographic data. average daily doses of the rest of the drugs were comparable to the American Society of Hypertension and the International Society of Hypertension guidelines (ASH/ ISH).

\begin{tabular}{|c|c|c|c|}
\hline Variable & Number (\%) & Range & Mean \pm Standard deviation \\
\hline Age (years) & $101(100)$ & & \\
\hline $18-59$ years & $59(58.4)$ & $34-76$ & $57.67 \pm 9.20$ \\
\hline$\geq 60$ years & $42(41.6)$ & & \\
\hline Sex & \multicolumn{3}{|c|}{$101(100)$} \\
\hline Male & \multicolumn{3}{|c|}{$51(50.5)$} \\
\hline Female & \multicolumn{3}{|c|}{$50(49.5)$} \\
\hline Height $(\mathrm{cm})$ & $84(83.2)$ & $81-182$ & $160.95 \pm 13.12$ \\
\hline Weight (kg) & $100(99)$ & $51.20-117.30$ & $84.03 \pm 15.70$ \\
\hline Body mass index $\left(\mathrm{kg} / \mathrm{cm}^{2}\right)$ & $84(83.2)$ & $19.84-48.68$ & $32.19 \pm 6.09$ \\
\hline Fasting serum glucose $(\mathrm{mmol} / \mathrm{L})$ & $48(47.5)$ & $3.4-22.6$ & $9.93 \pm 4.17$ \\
\hline Random serum glucose $(\mathrm{mmol} / \mathrm{L})$ & $55(54.5)$ & $3.3-20.1$ & $10.82 \pm 3.98$ \\
\hline HbA1c (\%) & $101(100)$ & $4.70-14.80$ & $8.76 \pm 1.91$ \\
\hline $\begin{array}{c}\text { Nephropathy status } \\
\text { With nephropathy } \\
\text { Without nephropathy }\end{array}$ & \multicolumn{2}{|c|}{$24(23.8)$} & 77 (76.2) \\
\hline Serum creatinine $(\mu \mathrm{mol} / \mathrm{L})$ & $101(100)$ & $40.0-633.0$ & $91.72 \pm 71.19$ \\
\hline Urea $(\mathrm{mmol} / \mathrm{L})$ & $101(100)$ & $1.90-25.70$ & $6.63 \pm 3.59$ \\
\hline Urinary albumin (mg/L) & $90(89.1)$ & $3.0-3864.10$ & $325.71 \pm 716.25$ \\
\hline Systolic blood pressure at visit 1 ( $\mathrm{mmHg}$ ) (prior to the study) & $101(100)$ & $112-198$ & $148.86 \pm 18.53$ \\
\hline Diastolic blood pressure at visit 1 ( $\mathrm{mmHg}$ ) (prior to the study) & $101(100)$ & $40-100$ & $75.58 \pm 12.58$ \\
\hline Systolic blood pressure at visit 2 ( $\mathrm{mmHg}$ ) (study start) & $101(100)$ & $100-201$ & $149.56 \pm 19.64$ \\
\hline Diastolic blood pressure at visit $2(\mathrm{mmHg})$ (study start) & $101(100)$ & $42-120$ & $77.06 \pm 13.31$ \\
\hline $\begin{array}{c}\text { Comorbidities } \\
\text { Dyslipidemia } \\
\text { Diabetic retinopathy } \\
\text { Ischemic heart disease } \\
\text { Diabetic neuropathy } \\
\text { Hypothyroidism } \\
\text { Knee osteoarthritis }\end{array}$ & $\begin{array}{l}63(62.4) \\
22(21.8) \\
19(18.8) \\
16(15.4) \\
15(14.9) \\
11(10.9)\end{array}$ & & \\
\hline $\begin{array}{l}\text { Hypoglycemic agents } \\
\text { Metformin } \\
\text { Gliclazide } \\
\text { As part insulin }\end{array}$ & $\begin{array}{l}75(74.3) \\
41(40.6) \\
26(25.7)\end{array}$ & & \\
\hline $\begin{array}{c}\text { Other drugs } \\
\text { Aspirin } \\
\text { Rosuvastatin } \\
\text { Esomeprazole } \\
\text { Atorvastatin }\end{array}$ & $\begin{array}{l}64(63.4) \\
63(62.4) \\
29(28.7) \\
28(27.7)\end{array}$ & & \\
\hline
\end{tabular}


Table 2: Demographic data.

\begin{tabular}{|c|c|c|c|c|}
\hline Drug & Number of patients & Range & Mean \pm Standard deviation & Recommended dose (mg) \\
\hline Amlodipine & 34 & $5-10$ & $8.68 \pm 2.24$ & $2.5-10$ \\
\hline Furosemide & 13 & $20-200$ & $60 \pm 48.30$ & $40-80$ \\
\hline Bisoprolol & 18 & $2.5-10$ & $5.56 \pm 2.20$ & $5-10$ \\
\hline Indapamide & 14 & 1.5 & $1.5 \pm 0$ & $1.25-2.5$ \\
\hline Irbesartan & 33 & $150-300$ & $186.36 \pm 65.28$ & $150-300$ \\
\hline Lisinopril & 33 & $5-25$ & $12.42 \pm 6.50$ & $5-40$ \\
\hline Atenolol & 7 & $25-100$ & $50 \pm 25$ & $25-100$ \\
\hline Carvedilol & 8 & $12.5-50$ & $34.38 \pm 17.36$ & $6.25-50$ \\
\hline Nifedipine & 4 & $30-60$ & $45 \pm 17.32$ & $30-90$ \\
\hline Hydralazine & 4 & $50-100$ & $68.75 \pm 23.94$ & $20-200$ \\
\hline Propranolol & 1 & 20 & 20 & $80-320$ \\
\hline Spironolactone & 2 & $25-100$ & $62.5 \pm 53.03$ & $12.5-50$ \\
\hline Hydrochlorothiazide & 1 & 50 & 50 & $12.5-50$ \\
\hline
\end{tabular}

\section{Degree of Control of Blood Pressure}

Among 101 hypertensive diabetic patients, 16 (15.8\%) had controlled systolic blood pressure, and 57 (56.4\%) had controlled

Table 3: Degree of control of blood pressure in 101 patients. diastolic blood pressure (Table 3). Table 3 shows 6 patients with systolic blood pressure $\geq 180$ and 1 patient with diastolic blood pressure $\geq 110$.

\begin{tabular}{|c|c|c|c|c|c|c|}
\hline Blood pressure & \multicolumn{7}{|c|}{ Degree of control } \\
\hline Systolic blood pressure (mmHg) & $<120$ & $120-129$ & $130-139$ & $140-159$ & $160-179$ & $\geq 180$ \\
\cline { 2 - 7 } Number (\%) & $5(5.0)$ & $11(10.9)$ & $14(13.9)$ & $42(41.6)$ & $23(22.8)$ & $6(5.9)$ \\
\hline Diastolic blood pressure (mmHg) & $<80$ & $80-84$ & $85-89$ & $90-99$ & $100-109$ & $\geq 110$ \\
\cline { 2 - 7 } & $57(56.4)$ & $14(13.9)$ & $14(13.9)$ & $11(10.9)$ & $4(4.0)$ & $1(1.0)$ \\
\hline
\end{tabular}

\section{Adverse Drug Reactions of Antihypertensive Drugs}

Table 4 shows adverse drug reactions that are directly responsible for drug discontinuation. The most common adverse drug reactions were pedal edema and dry cough. There were many cases that reported adverse reactions associated with lisinopril. There were no reported side effects for bisoprolol, which was used by many patients.

Table 4: Adverse drug reactions.

\begin{tabular}{|c|c|c|}
\hline Reported event & Drug & Number of patients \\
\hline Dry cough & Lisinopril & 3 \\
\hline Dry cough & Irbesartan & 1 \\
\hline Shortness of breath & Lisinopril & 2 \\
\hline Proteinuria & Co-Diovan & 1 \\
\hline Hyperkalemia & Irbesartan & 3 \\
\hline Skin lesions & Indapamide & 1 \\
\hline Itchiness & Lisinopril & 1 \\
\hline Pedal edema & Amlodipine & 5 \\
\hline Dizziness & Amlodipine & 1 \\
\hline Hyponatremia & Spironolactone & 1 \\
\hline Hyponatremia & Indapamide & 1 \\
\hline Weakness and sleepiness & Exforge-HCT & 1 \\
\hline
\end{tabular}

\begin{tabular}{|c|c|c|}
\hline Not tolerating the drug & Indapamide & 1 \\
\hline Polyuria & Co-Diovan & 1 \\
\hline High creatinine & Lisinopril & 1 \\
\hline Hypokalemia & Frusemide & 1 \\
\hline $\begin{array}{c}\text { Chest pain and shortness of } \\
\text { breath }\end{array}$ & Atenolol & 1 \\
\hline Hyperkalemia & Lisinopril & 1 \\
\hline Hyperkalemia & Spironolactone & 1 \\
\hline Tiredness & Frusemide & 1 \\
\hline $\begin{array}{c}\text { A pruritic sensation at the } \\
\text { back of the throat }\end{array}$ & Amlodipine & 1 \\
\hline $\begin{array}{c}\text { Significant fatigue during } \\
\text { daytime }\end{array}$ & Amlodipine & 1 \\
\hline Loss of libido & Atenolol & 2 \\
\hline
\end{tabular}

\section{Drug Groups Prescribed and Dispensed to Hypertensive}

\section{Diabetic Patients}

Antihypertensive treatment was divided into 6 drug groups (Figure 1), with ARB being the most commonly prescribed (53.5\%), followed by diuretics (49.5\%). Vasodilators are among the least prescribed drugs. Administration of different dosage combinations in hypertensive diabetic patients. Multiple drug therapy is, by far the most widely prescribed drug regimen (Figure 2). 59.4\% of 
patients were on multiple drug regimens, $30.7 \%$ were on a single drug and, $24.8 \%$ were on fixed-dose combination only.

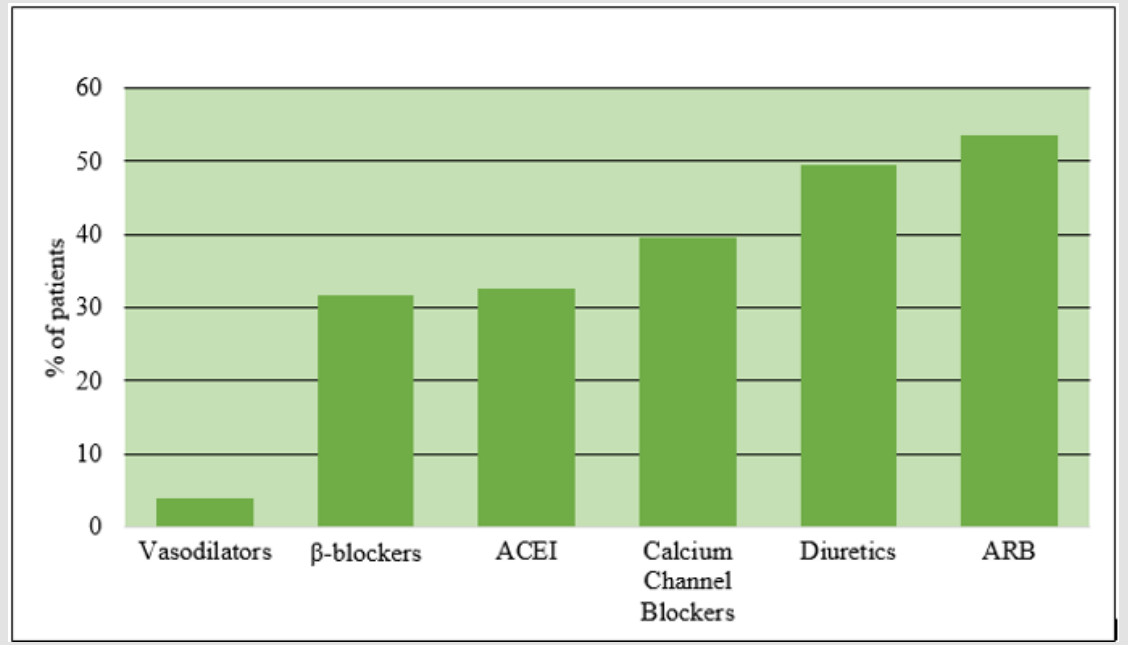

Figure 1: Percentage of patients who used different groups of antihypertensive drugs.

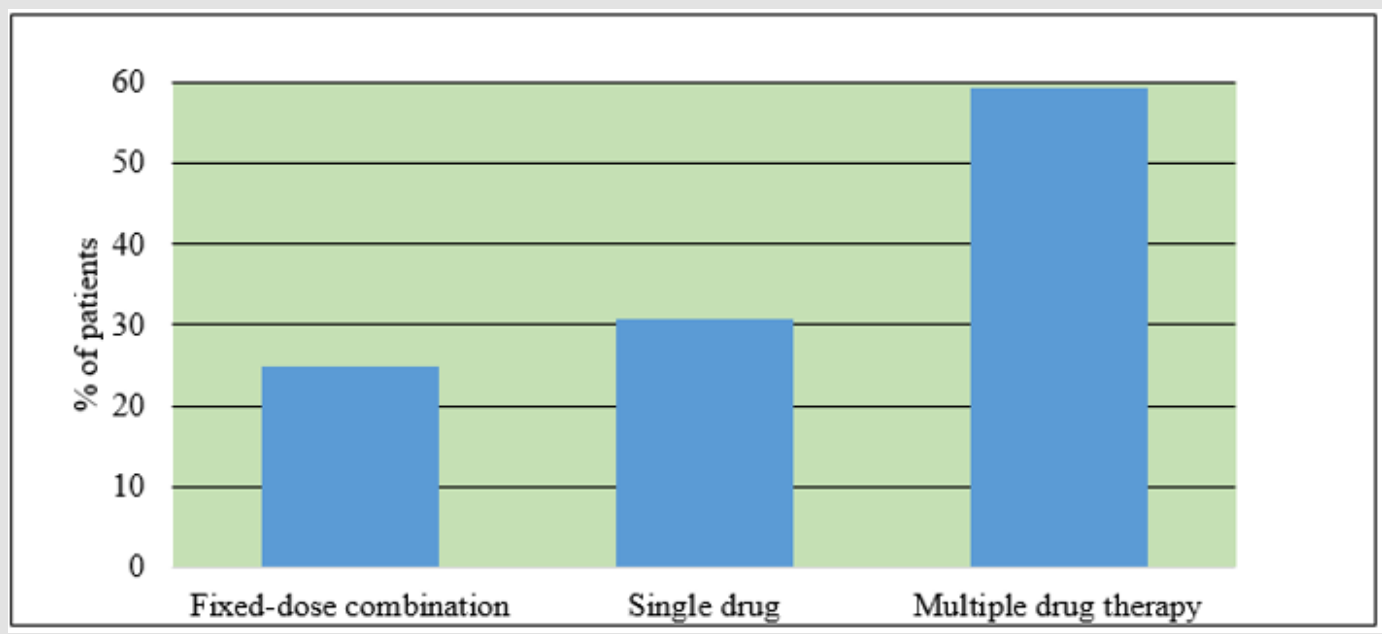

Figure 2: Percentage of patients who used different drug regimens of antihypertensive drugs.

\section{Fixed-Dose Combinations Therapy}

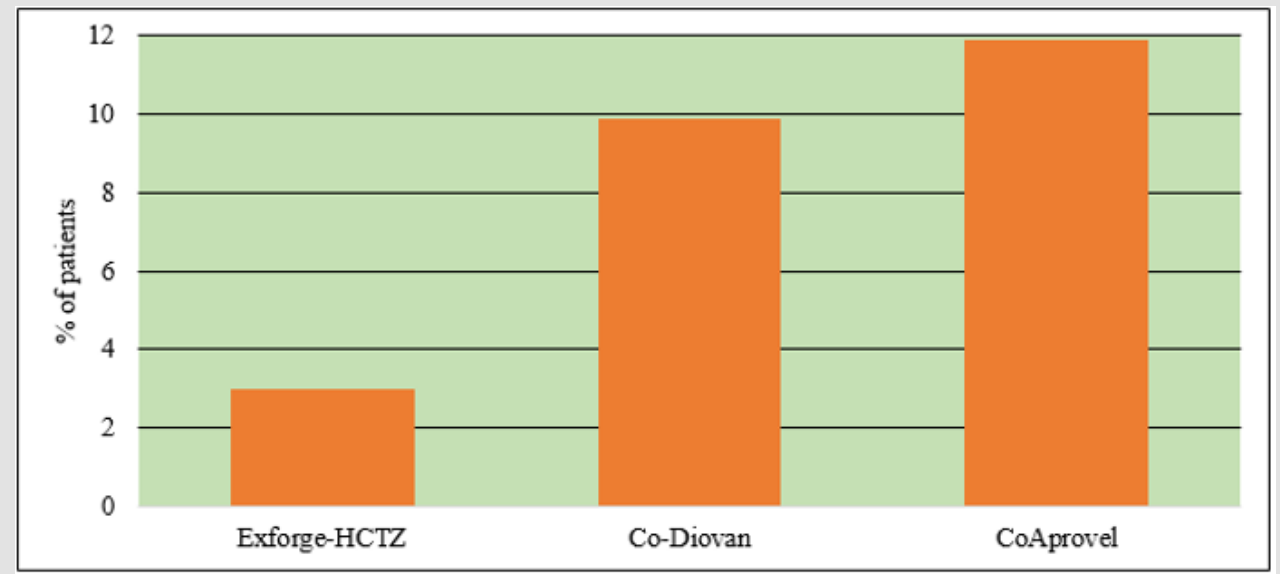

Figure 3: Percentage of patients who used a fixed-dose combination of antihypertensive drugs. 
The fixed-dose combinations identified included Co-Diovan, CoAprovel and Exforge-HCTZ which are comprised of valsartan / hydrochlorothiazide, irbesartan /hydrochlorothiazide and valsartan/ amlodipine/ hydrochlorothiazide, respectively. 25 patients (24.8\%) used fixed-dose combinations. Of the 25 patients, 12 (48\%), 10 (40\%), and 3 (12\%) were on valsartan/ hydrochlorothiazide, irbesartan/ hydrochlorothiazide, and amlodipine/valsartan/ hydrochlorothiazide combinations, respectively (Figure 3).

\section{Drug Groups Dispensation in Two Age Groups}

Figure 4 shows that there was a significant difference in the percentage of patients who used $\beta$-blockers $(P=0.024)$ in the age group ( $\geq 60$ years) from patients of the age group (18-59 years). There was no significant difference for the other drug groups.

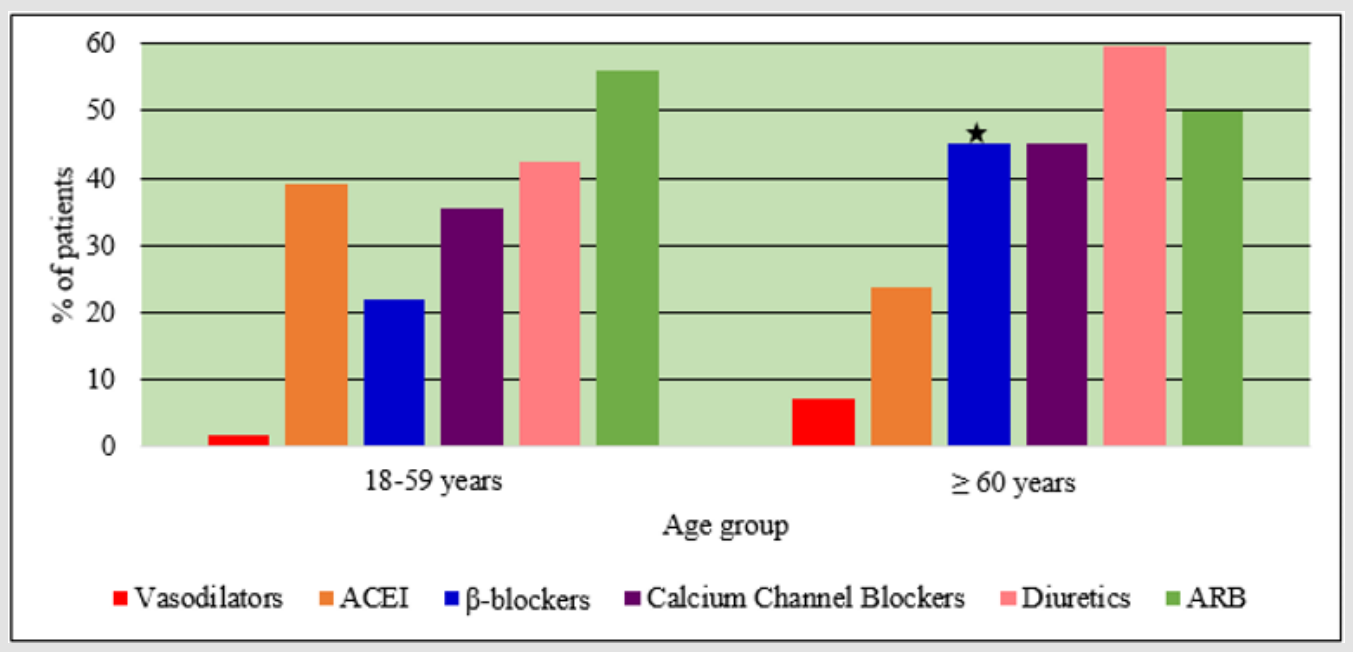

Figure 4: Percentage of patients who used different groups of antihypertensive drugs categorized by age group. Note: $\star(\mathrm{P}<0.05)$ significant from patients of age group (18-59 years)

Drug Groups Dispensation in Patients with and without

\section{Nephropathy}

As shown in (Figure 5), vasodilators $(P=0.041)$, calcium channel blockers $(P=0.017)$, and $\beta$-blockers $(P=0.003)$ showed higher use percentages in patients with nephropathy compared to patients without nephropathy, whereas the percentage of ACEI (P = 0.030 ) was higher in patients without nephropathy. There was no significant difference for the other drug classes.

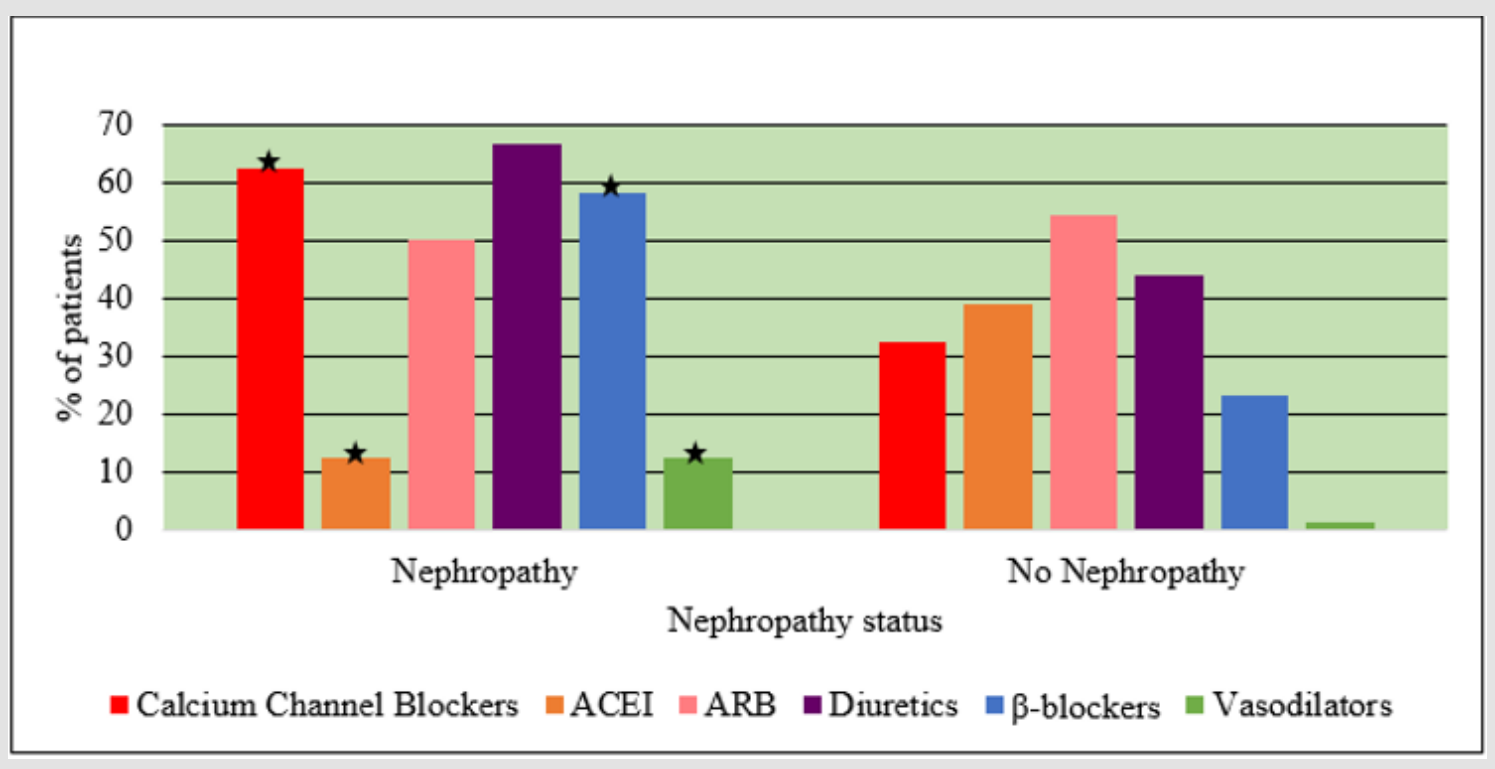

Figure 5: Percentage of patients who used different groups of antihypertensive drugs categorized by nephropathy status.

Note: $\star(\mathrm{P}<0.05)$ significant from patients without nephropathy. 


\section{Single Drug Therapy}

Four single drugs were prescribed in hypertensive diabetic patients (Figure 6). The drug with the highest percentage of prescriptions (48.4\%) was found to be irbesartan, followed by lisinopril (41.9\%). The remaining two drugs, amlodipine, and bisoprolol, were with the lowest percentages $(6.5 \%$ and $3.2 \%$, respectively) among the four drugs.

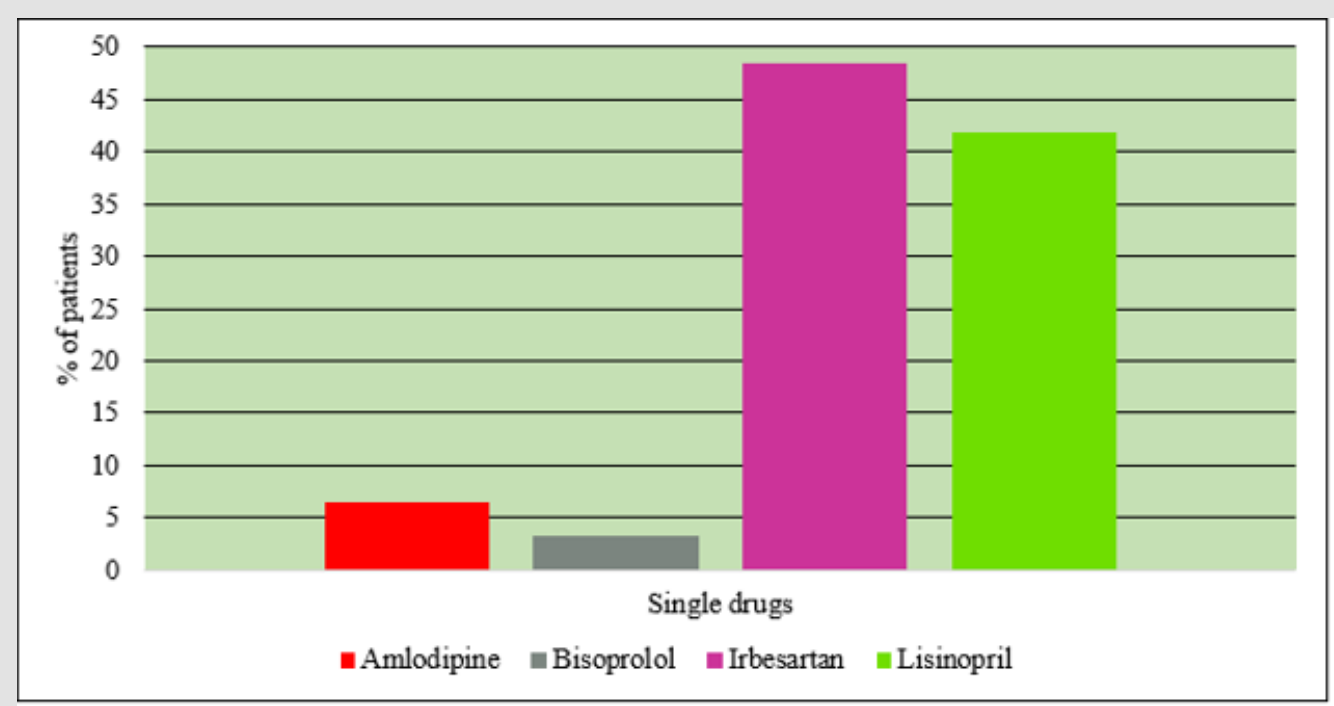

Figure 6: Percentage of patients who used a single antihypertensive drug.

Dispensation of Antihypertensive Drugs in Hypertensive

\section{Diabetic Patients}

Figure 7 shows that the most commonly prescribed drug was amlodipine (33.7\%). It was the most commonly prescribed calcium channel blocker. The most frequently prescribed ARB was irbesartan (32.7\%). The most frequently prescribed ACE inhibitor was lisinopril (31.7\%). Bisoprolol (13.9\%) belongs to the most frequently prescribed $\beta$-blocker. Indapamide (12.9\%) was the most frequently prescribed diuretic. Hydralazine (4.0\%) was the most commonly prescribed vasodilator.

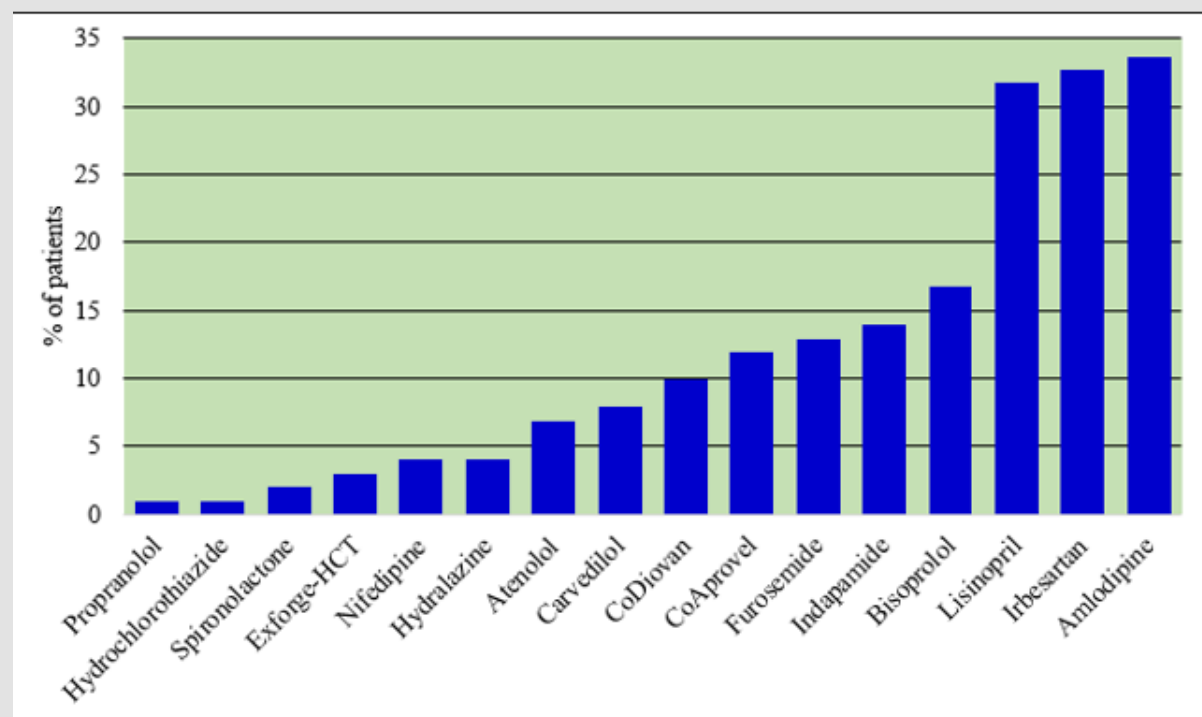

Figure 7: Percentage of patients who used different antihypertensive drugs.

\section{Antihypertensive Drugs Dispensation in Two Age Groups}

The utilization of furosemide differed significantly $(\mathrm{P}=0.014)$ in patients of age group ( $\geq 60$ years) from patients of age group
(18-59 years) as demonstrated in Figure 8. There was no significant difference for the other drugs. 

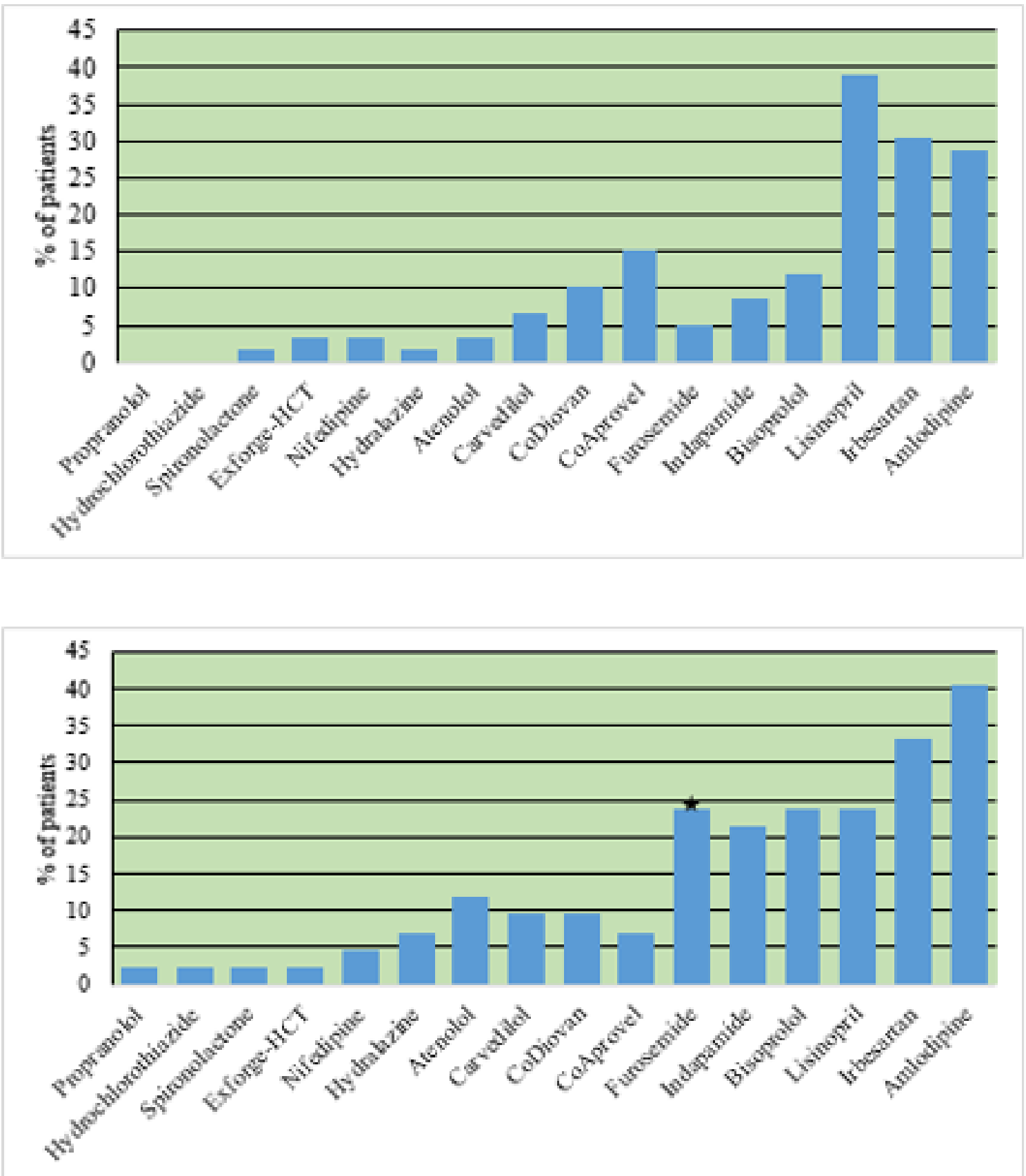

Figure 8: Percentage of patients who used different antihypertensive drugs categorized by age group.

Note: $\star(\mathrm{P}<0.05)$ significant from patients of age group (18-59 years).

\section{Antihypertensive Drugs Dispensation in Patients with and without Nephropathy}

Amlodipine $(\mathrm{P}=0.007)$, furosemide $(\mathrm{P}=0.012)$, bisoprolol $(\mathrm{P}=$ 0.025), and hydralazine ( $\mathrm{P}=0.041)$ showed higher use percentages in nephropathy compared to patients with no nephropathy. Lisinopril $(\mathrm{P}=0.030)$ showed higher use percentage in patients without nephropathy (Figure 9).

\section{Treatment with Different Drug Combinations}

Figure 10 shows the use of $\geq 2$ antihypertensive drug combinations and diverse ways of combination for the management of hypertension in diabetic patients. Thirty-one drug combinations of the designated drugs were identified to be prescribed for the patients. The largest set of combinations consisted of 5 different antihypertensive drugs, which included indapamide, atenolol, amlodipine, hydralazine, and irbesartan. 

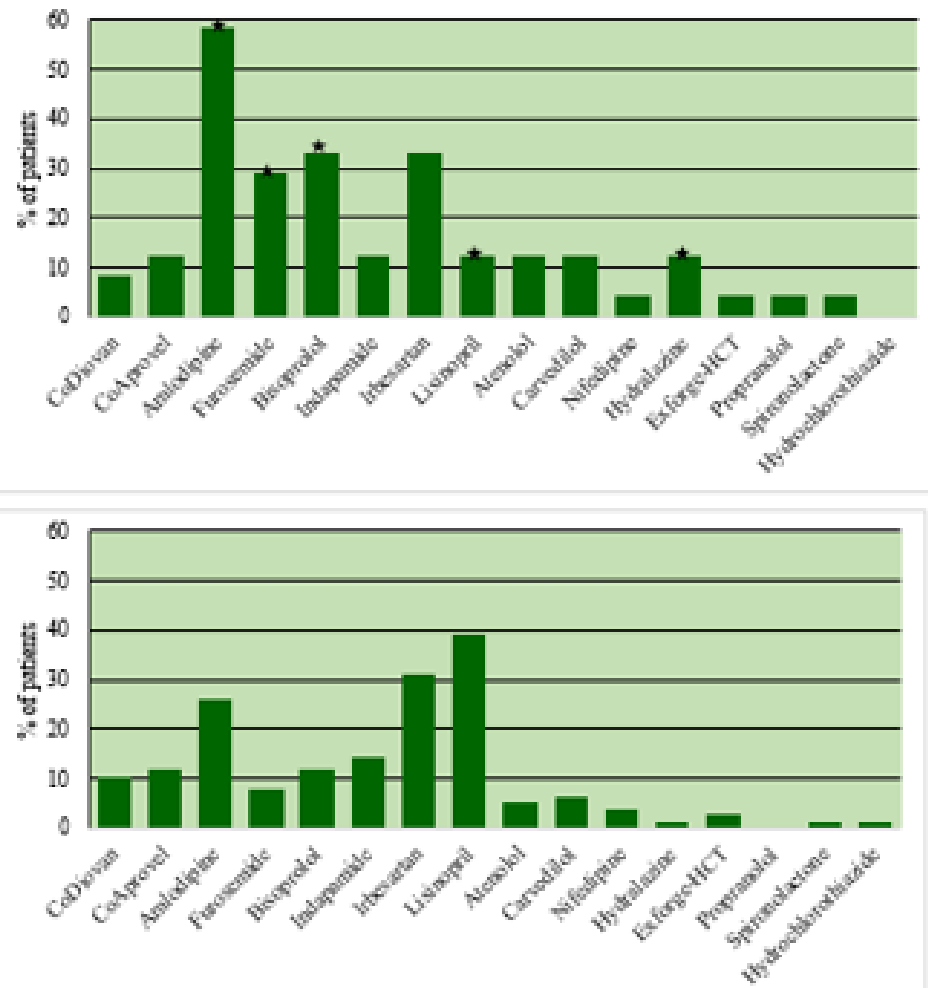

Figure 9: Percentage of patients who used different antihypertensive drugs categorized by nephropathy status. Note: $\star(\mathrm{P}<0.05)$ significant from patients without nephropathy.

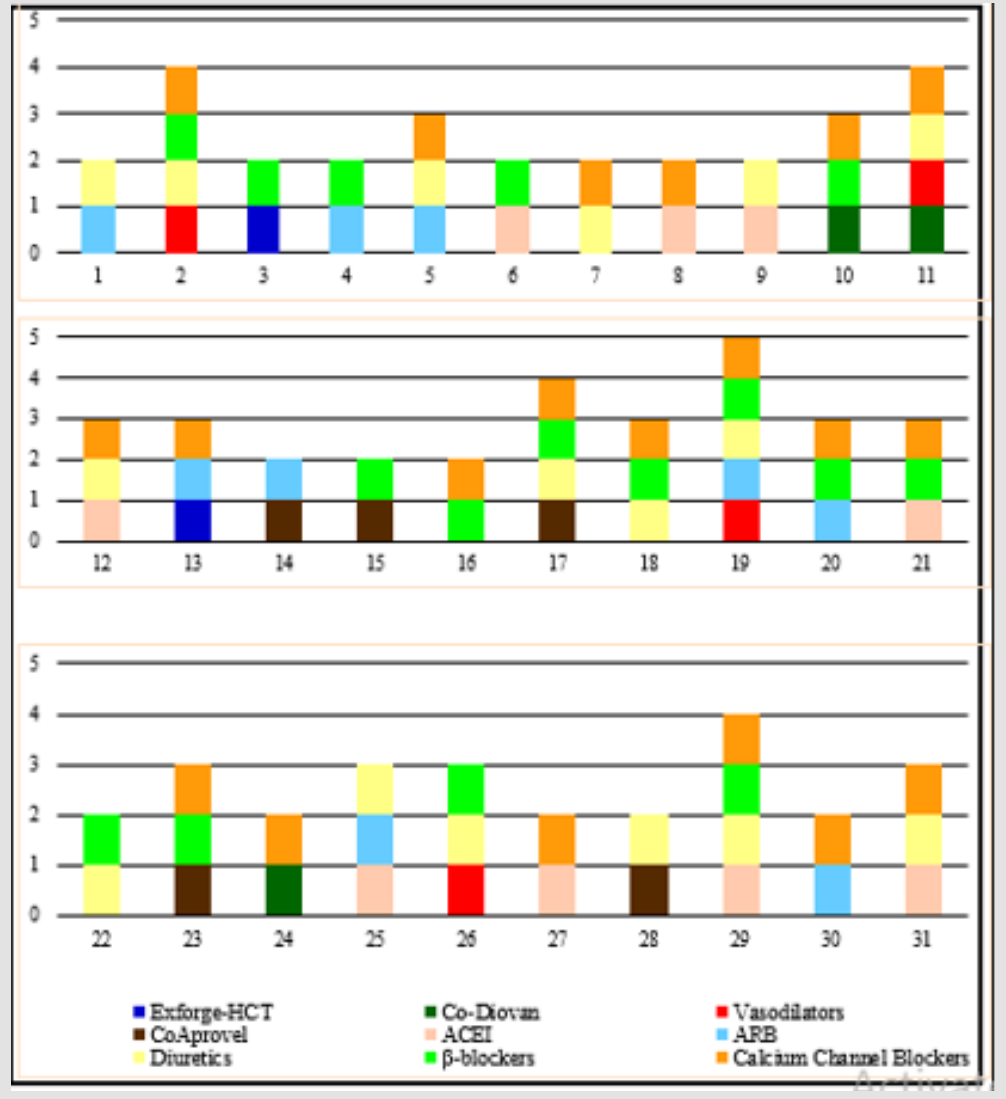

Figure 10: All drug combinations used by hypertensive diabetic patients. 


\section{Discussion}

ARB is the most commonly prescribed drug group (53.5\%), followed by diuretics (49.5\%). Irbesartan (32.7\%), an angiotensin II receptor blocker, had the highest use percentage in this drug group. Indapamide (12.9\%) is the most frequently prescribed diuretic. These findings are consistent with recommendations from the Canadian guidelines [36] as the first-line management of hypertension in diabetic patients with chronic kidney disease is ACEI or ARB alone or in combination with another class [37]. Guidelines recommend the use of ACEI and ARB, preferably over the use of other drugs as single-drug therapy, and this reflected upon the lower utilization rates of the other antihypertensive drugs by physicians indicating good response in following evidencebased guidelines. This will ameliorate the high level of adverse drug reactions and renal failure cases.

If blood pressure is not controlled on ACEI/ARB alone, then it may be more effective to add either a CCB or a thiazide diuretic. Although it is true that an additional drug like calcium channel blockers or a thiazide diuretic can be added, the Canadian guideline recommendations state that the combination of an ACE inhibitor or ARB, and a calcium channel blocker is the preferred and superior combination therapy regimen over the combination of ACE inhibitor or ARB, and a thiazide diuretic for hypertensive diabetic patients [38]. On the contrary, some patients in this study were prescribed ACEI or ARB with a diuretic.

Average daily dose comparisons demonstrated almost comparable dosages with ASH/ISH guidelines [39]. However, because of the scarce number of patients who were on spironolactone and propranolol, this does not provide a reliable comparison because of insufficient patients' number. The average daily dose was not considered to be borderline high or low. Despite the emergence of multiple new challenges affecting blood pressure control, physicians complied with guideline recommendations in prescribing correct and appropriate dosages to the patients. Physicians are recommended to monitor blood pressure values closely after the administration of antihypertensive drugs. The ensuing high percentage of patients with uncontrolled blood pressure can be attributed to the fact that some patients hesitate to look after their blood pressure, and some of them may not have home blood pressure monitors. Antihypertensive drugs were switched after the management of patients with an emergent situation of extremely elevated blood pressure values. Some patients were put on the same drugs because they were not compliant. Others had their drugs discontinued and changed to more potent drugs as they will help effectively in the reduction of blood pressure. It is recommended for the physicians to stress on drug compliance and maintenance of a healthy diet.

The high percentage of patients on multiple drug regimens indicates that many patients require at least two agents to achieve their target blood pressure. This is consistent with other studies that showed that monotherapy is inadequate in the majority of patients with hypertension. It has been estimated that $40-60 \%$ of patients will require more than one drug to achieve target blood pressure control (i.e., diastolic blood pressure < 90mm Hg) [40]. This is particularly true for patients with diabetes or chronic kidney disease, where multiple agents are required for about two-thirds of patients to achieve blood pressure $<130 / 80 \mathrm{~mm} \mathrm{Hg} \mathrm{[41].} \mathrm{A}$ relatively large percentage $(33.7 \%)$ of patients were on amlodipine. In this regard, amlodipine was utilized alone in two patients with nephropathy. The prescription of amlodipine alone in these two patients does not comply with guidelines that recommend concomitant combinations of calcium channel blockers with other drugs in nephropathy. Prescription of a dihydropyridine calciumchannel blocker to treat a patient without proteinuria may lead to some manifestations such as the development of proteinuria and potentially higher risk of chronic renal disease. However, current guidelines recommend the use of dihydropyridine calcium channel blockers as an initial treatment in hypertensive diabetic patients without proteinuria. The addition of a CCB to a combination of indapamide and perindopril reduced the relative risk of death from $5 \%$ down to $28 \%$. Many patients (53.5\%) were on ARB, with a higher percentage than ACEI. The excellent tolerability and high efficacy of ARB have accounted for both the low discontinuation rates and improved patient compliance.

The reasons for poor blood pressure control are multifactorial. Factors pertaining to patients include adherence, commitment, socioeconomic factors, and age; those related to physicians include unfamiliarity with hypertension treatment guidelines, inappropriate treatment, and satisfaction of patient blood pressure levels above the recommended targets. Because of the small number of cases in each grade of hypertension, the grade of hypertension could not be used to verify any association between control of blood pressure and compliance status or smoking. Instead, the degree of control of blood pressure with an interval of $10 \mathrm{mmHg}$ for systolic blood pressure and $5 \mathrm{mmHg}$ for diastolic blood pressure was used to allocate 101 hypertensive diabetic patients in a hierarchical fashion as demonstrated in Table 4. Patients' factors in regard to the effectiveness of treatment remain a major issue here as what can be deduced after knowing that physicians comply with guideline recommendations is that patients having bad perception and attitude towards doctors' advice is unequivocal. Despite various treatment options, blood pressure control in hypertensive diabetic patients remains a challenge. High rates of uncontrolled blood pressure are probably associated with comorbidities.

There was a substantial significant difference between patients with and without nephropathy in the utilization of the drug bisoprolol. It has been recently described that lower dosages of thiazides $(6.25 \mathrm{mg})$ have been combined with other drugs to prevent individual adverse events from happening yet achieve efficacy. In a trial, $6.25 \mathrm{mg}$ of hydrochlorothiazide was administered with bisoprolol. The combination of bisoprolol 2.5 
$\mathrm{mg} /$ hydrochlorothiazide $6.25 \mathrm{mg}$ helped to reach the same level of diastolic blood pressure reduction as four times as much as the single constituents. Previous studies described the capability of this low-dose thiazide- $\beta$-blocker combination to control blood pressure, likewise, to titrated dosages of a calcium antagonist or an ACE inhibitor. The combination not only provided better or similar efficacy but also it was well-tolerated with a lower number of patients experiencing withdrawals. Obviously, $\beta$-blockers play a role in the reduction of cardiovascular risk in the treatment of patients with non-diabetic or diabetic renal disease. Other agents like calcium channel blockers help to achieve blood pressure targets. Selective $\beta 1$-blockers do not offer any benefits in terms of improved glycemic control or renoprotection. Because there was a significant difference for $\beta$-blockers in the age group ( $\geq 60$ years), this indicates that there is a high number of old patients with ischemic heart disease. This is an advantageous utilization of $\beta$-blockers in patients with ischemic heart disease but the problem lies in the fact that $\beta$-blockers can obscure the symptoms of hypoglycemia.

In this study, the most frequently reported adverse drug reaction was pedal edema. In another study, dizziness was the only adverse event seen significantly more frequently with combination therapy than with monotherapy. The large number of patients who were on amlodipine accounted for the high rate of this adverse reaction among hypertensive diabetic patients. Antihypertensive drugs implicated in causing other adverse events were also discontinued and switched to other drugs. There were many cases that reported adverse reactions associated with Lisinopril, and this explains the high utilization percentage of irbesartan compared to lisinopril. Apparently, inappropriate prescription poses a risk of adverse drug reactions. There were no reported side effects for bisoprolol, which was used by many patients, and this could be the reason why it is highly prescribed in the elderly and nephropathy patients. A study has found that the most frequently reported antihypertensive drugs to cause adverse drug reactions in decreasing order of reports were thiazides, ACEI, and CCB, $\beta$-blockers, and ARB. One patient was on a large set of combinations consisting of 5 different antihypertensive drugs, which included indapamide, atenolol, amlodipine, hydralazine, and irbesartan.

As with any study, there were some limitations and challenges. There are other comorbidities, which affect the prescription of antihypertensive drugs, such as chronic obstructive pulmonary disease, ischemic heart disease, and heart failure. The study was done in SQUH hospital, a tertiary hospital, and this does not represent the entire population. The drugs taken by patients who have controlled and uncontrolled blood pressure were not demonstrated in figures. Although the sample size is relatively enough for study purposes, chi-square was sensitive to sample size, especially when patients were divided according to drugs and drug groups. Given the paucity of data for smoking status, an association between smoking and control of blood pressure could not be assessed as there was a very low number of smokers.

\section{Conclusion}

$53.5 \%$ of patients were on ARB. $49.5 \%$ were treated with diuretics. $59.4 \%$ of the patients were on multiple drug therapy. Average daily dosages were almost comparable with ASH/ISH guidelines. The age group $(\geq 60)$ used $\beta$-blockers with a higher percentage than the age group (18-59). Vasodilators, calcium channel blockers, and $\beta$-blockers showed higher use percentages in nephropathy compared to patients with no nephropathy, whereas the percentage of ACEI was higher in no nephropathy status. $84.2 \%$ of patients had uncontrolled systolic blood pressure, and $43.6 \%$ of patients had uncontrolled diastolic blood pressure. Thirty-one drug combinations of the designated drugs were identified to be prescribed for the patients (Appendix).

\section{Acknowledgment}

I'm thankful to Prof. Nicholas Woodhouse, Nurses Stella and Sophie, Prof. Hamza Babiker, Dr. Ammar Boudaka, and Dr. Syed Rizvi for providing the necessary guidance, support, valuable advice, and comments from the beginning of the research project to the completion of the study.

\section{References}

1. Agodoa LY, Appel L, Bakris GL, Beck G, Bourgoignie J, et al. (2001) Effect of ramipril vs amlodipine on renal outcomes in hypertensive nephrosclerosis: a randomized controlled trial. JAMA 285(21): 27192728.

2. Al Lawati JA, Panduranga P, Al Shaikh HA, Morsi M, Mohsin N, et al. (2015) Epidemiology of diabetes mellitus in Oman: results from two decades of research. Sultan Qaboos Univ Med J 15(2): e226-e233.

3. Anwer Z, Sharma R, Garg V, Kumar N, Kumari A (2011) Hypertension management in diabetic patients. Eur Rev Med Pharmacol Sci 15: 12561263.

4. Arifulla M, John LJ, Sreedharan J, Muttappallymyalil J, Cheriathu J (2015) Use of antihypertensive medications in patients with type -2 diabetes in Ajman, UAE. Acta Med Iran 53: 129-133.

5. Armstrong C (2014) JNC8 guidelines for the management of hypertension in adults. Am Fam Physician 90(7): 503-504.

6. Ayodele OE, Alebiosu CO, Salako BL (2004) Diabetic nephropathy--a review of the natural history, burden, risk factors and treatment. J Natl Med Assoc 96(11): 1445-1454.

7. Bakris GL (2003) Role for beta-blockers in the management of diabetic kidney disease. Am J Hypertens 16: 7s-12s.

8. Bakris GL, Williams M, Dworkin L, Elliott WJ, Epstein M, et al. (2000) Preserving renal function in adults with hypertension and diabetes: a consensus approach. National Kidney Foundation Hypertension and Diabetes Executive Committees Working Group. Am J Kidney Dis 36(3): 646-661.

9. Berlowitz DR, Ash AS, Hickey EC, Glickman M, Friedman R (2003) Hypertension management in patients with diabetes: the need for more aggressive therapy. Diabetes Care 26(2): 355-359.

10. Bolli P (2008) Treatment resistant hypertension. Am J Ther 15: 351-355.

11. Brown MJ, Cruickshank JK, Dominiczak AF, MacGregor GA, Poulter NR, et al. (2003) Better blood pressure control: how to combine drugs. J Hum Hypertens 17(2): 81-86.

12. Calderon Larranaga A, Diaz E, Poblador Plou B, Gimeno Feliu LA, Abad Diez JM (2016) Non-adherence to antihypertensive medication: The role of mental and physical comorbidity. Int J Cardiol 207: 310-316. 
13. Cheung BM, Wong YL, Lau CP (2005) Queen Mary utilization of antihypertensive drugs study: side-effects of antihypertensive drugs. J Clin Pharm Ther 30(4): 391-399.

14. Chobanian AV, Bakris GL, Black HR, Cushman WC, Green LA, et al. (2003) Seventh report of the Joint National Committee on prevention, detection, evaluation, and treatment of high blood pressure. Hypertension 42: 1206-1252.

15. Dasgupta K, Quinn RR, Zarnke KB, Rabi DM, Ravani P, et al. (2014) The 2014 Canadian hypertension education program recommendations for blood pressure measurement, diagnosis, assessment of risk, prevention, and treatment of hypertension. Can J Cardiol 30(5): 485-501.

16. Demarie BK, Bakris GL (1990) Effects of different calcium antagonists on proteinuria associated with diabetes mellitus. Ann Intern Med 113(12): 987-988.

17. El Shafie K, Rizvi S (2010) Control of hypertension among type II diabetics. Oman Med J 25(1): 32-36.

18. Everett BM, Glynn RJ, Danielson E, Ridker PM (2008) Combination therapy versus monotherapy as initial treatment for stage 2 hypertension: a prespecified subgroup analysis of a community-based, randomized, open-label trial. Clin Ther 30(4): 661-672.

19. Ferner RE, Aronson JK (2006) Clarification of terminology in medication errors: definitions and classification. Drug Saf 29(11): 1011-1022.

20. Gabb GM, Mangoni AA, Anderson CS, Cowley D, Dowden JS, et al. (2016) Guideline for the diagnosis and management of hypertension in adults 2016. Med J Aust 205(2): 85-89.

21. Garber AJ (2000) Attenuating cardiovascular risk factors in patients with type 2 diabetes. Am Fam Physician 62(12): 2633-2642.

22. Guo F, He D, Zhang W, Walton RG (2012) Trends in prevalence, awareness, management, and control of hypertension among United States adults, 1999 to 2010. J Am Coll Cardiol 60(7): 599-606.

23. Johnson ML, Singh H (2005) Patterns of antihypertensive therapy among patients with diabetes. J Gen Intern Med 20(9): 842-846.

24. Kearney PM, Whelton M, Reynolds K, Muntner P, Whelton PK (2005) Global burden of hypertension: analysis of worldwide data. Lancet 365(9455): 217-223.

25. Khan N, McAlister FA (2006) Re-examining the efficacy of beta-blockers for the treatment of hypertension: a meta-analysis. CMAJ 174(12): 1737-1742.

26. Kurokawa K, Nangaku M, Saito A, Inagi R, Miyata T (2002) Current issues and future perspectives of chronic renal failure. J Am Soc Nephrol 13 (Suppl 1): S3-6.

27. Kvam FI, Ofstad J, Iversen BM (1998) Effects of antihypertensive drugs on autoregulation of RBF and glomerular capillary pressure in SHR. Am J Physiol 275(4): F576-584.

ISSN: 2574-1241

DOI: 10.26717/BJSTR.2021.32.005328

Khalil Al Ajmi. Biomed J Sci \& Tech Res

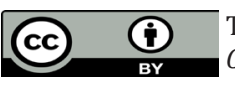

This work is licensed under Creative Commons Attribution 4.0 License

Submission Link: https://biomedres.us/submit-manuscript.php
28. Lindholm LH, Carlberg B, Samuelsson O (2005) Should beta blockers remain first choice in the treatment of primary hypertension? A metaanalysis. Lancet 366(9496): 1545-1553.

29. MacLeod MJ, McLay J (1998) Drug treatment of hypertension complicating diabetes mellitus. Drugs 56(2): 189-202.

30. Mancia G (2007) Optimal control of blood pressure in patients with diabetes reduces the incidence of macro and microvascular events. J Hypertens Suppl 25(1): S7-12.

31. Materson BJ, Reda DJ, Cushman WC (1995) Department of veteran's affairs single-drug therapy of hypertension study. Revised figures and new data. Department of Veterans Affairs Cooperative Study Group on Antihypertensive Agents. Am J Hypertens 8(2): 189-192.

32. Matheus AS, Tannus LR, Cobas RA, Palma CC, Negrato CA (2013) Impact of diabetes on cardiovascular disease: an update. Int J Hypertens 2013: 653789.

33. Oparil S, Silfani TN, Walker JF (2005) Role of angiotensin receptor blockers as monotherapy in reaching blood pressure goals. Am J Hypertens 18: 287-294.

34. Palmer SC, Mavridis D, Navarese E, Craig JC, Tonelli M, et al. (2015) Comparative efficacy and safety of blood pressure-lowering agents in adults with diabetes and kidney disease: a network meta-analysis. Lancet 385(9982): 2047-2056.

35. Schillinger D, Grumbach K, Piette J, Wang F, Osmond D, et al. (2002) Association of health literacy with diabetes outcomes. JAMA 288(4): 475-482.

36. Sica DA (2004) Current concepts of pharmacotherapy in hypertension: thiazide-type diuretics: ongoing considerations on mechanism of action. J Clin Hypertens (Greenwich) 6(11): 661-664.

37. Standl E, Erbach M, Schnell O (2012) What should be the antihypertensive drug of choice in diabetic patients and should we avoid drugs that increase glucose levels? Pro and Cons. Diabetes Metab Res Rev 28(Suppl 2): $60-66$

38. Stehouwer CD, Henry RM, Ferreira I (2008) Arterial stiffness in diabetes and the metabolic syndrome: a pathway to cardiovascular disease. Diabetologia 51(4): 527-539.

39. Weber MA, Schiffrin EL, White WB, Mann S, Lindholm LH, et al. (2014) Clinical practice guidelines for the management of hypertension in the community: a statement by the American Society of Hypertension and the International Society of Hypertension. J Clin Hypertens (Greenwich) 16(1): 14-26.

40. Weir MR (1998) The rationale for combination versus single-entity therapy in hypertension. Am J Hypertens 11(s7): 163-169.

41. Wenzel UO, Benndorf R, Lange S (2013) Treatment of arterial hypertension in obese patients. Semin Nephrol 33(1): 66-74.

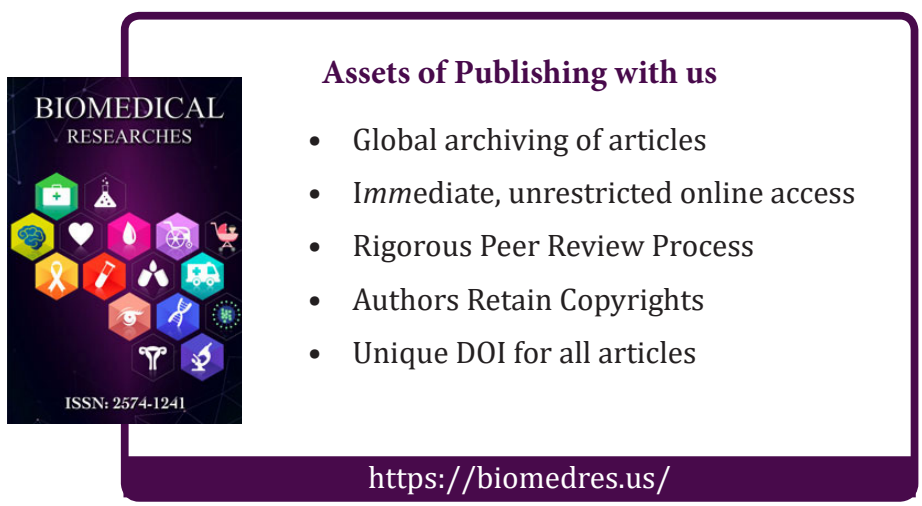

Copyright@ Khalil Al Ajmi | Biomed J Sci \& Tech Res | BJSTR. MS.ID.005328. 